\title{
New insights into the formation of volatile compounds in mainstream cigarette smoke
}

\author{
C. Liu $\cdot$ S. Feng $\cdot$ J. van Heemst $\cdot$ K. G. McAdam
}

Received: 16 October 2009/Revised: 18 December 2009 /Accepted: 4 January 2010 /Published online: 26 January 2010

(C) The Author(s) 2010. This article is published with open access at Springerlink.com

\begin{abstract}
A sampling system has been set up to monitor a group of volatile smoke analytes (nitric oxide, acetaldehyde, acetone, benzene, toluene, 1,3 butadiene, isoprene and carbon dioxide) from mainstream cigarette smoke on a puff-resolved basis. The system was able to record gas evolution profiles during puffing and interpuff periods without interruption (e.g. taking clearing puffs). Gas phase smoke analytes were sampled as close to the mouth end of the cigarette filter as possible in order to minimise any dead volume effect. The results revealed that, for some volatile species, a significant fraction (e.g. up to $30 \%$ for benzene) in the cigarette mainstream smoke had been generated during the preceding smoulder period. These species were trapped or absorbed within the cigarette rod and then subsequently eluted during the puff. The identification of the two sources of the mainstream smoke, a smouldering source and a puffing source, has not been reported before. The observation contributes to the fundamental knowledge of the cigarette smoke formation and may have implications on wider smoke chemistry and associated effects.
\end{abstract}

Keywords Real-time sampling $\cdot$ Cigarette $\cdot$ Smoke chemistry $\cdot$ Volatile species

\section{Introduction}

Smoke formation inside a burning cigarette is complex and governed by many physical and chemical processes [1-4].

C. Liu $(\varangle) \cdot$ S. Feng $\cdot$ J. van Heemst $\cdot$ K. G. McAdam

Group R\&D Centre, British American Tobacco,

Regents Park Road,

Southampton SO15 8TL, UK

e-mail: Chuan_Liu@bat.com
Understanding these processes may help to design cigarettes with potentially reduced toxicant levels [5]. The mainstream smoke emitted from the mouth end of a cigarette is mainly produced by combustion and pyrolysis reactions as well as distillation processes in the burning tip (or coal) of the cigarette when the cigarette is puffed. Subsequent nucleation, condensation, adsorption, filtration and dilution processes occur along the tobacco rod and the cigarette filter as the smoke is drawn through the tobacco rod. The complexity of cigarette smoke composition reflects the fact that tobacco is a plant material [4]. The effects of modern cigarette design variables, the use of additives and different puffing patterns have also been evaluated for their effects on smoke chemistry [6-8]. The fundamental understanding behind the cigarette smoke formation processes has been described in numerous book chapters and literature reviews [1-4]. They not only highlight the achievements made over the past 50 years of tobacco research but also point out that our understanding of the subject is still inadequate [5], and more efforts are needed in this area in order to develop reduced toxicant cigarettes.

Probing a complex system such as a burning cigarette requires the application of the latest modern analytical techniques. Routine smoke analyses, which cover the socalled Hoffmann analytes [1, 4], have been extensively studied under various international or regulatory stipulated smoking conditions [7-13]. These analyses are generally aimed at comparing yields of smoke toxicants under a defined set of machine-smoking parameters. The data produced are sometimes used to establish relationships that may be applied to assess new or modified cigarette products. Some relationships, such as an approximately linear increase in particulate phase analytes (e.g. benzo $[a]$ pyrene) with increasing tar levels, are easy to understand as they agree with the basic understanding of smoke genera- 
tion and filtration [2]. Other relationships, such as those which show a positive (e.g. for nitric oxide or benzene) or a negative (e.g. formaldehyde) intercept on the toxicant yield vs. tar plots, are more puzzling, as they imply a source or a sink for these analytes for low tar cigarettes [7-9]. The smoke generation and collection procedures involved in the routine smoke analyses are designed primarily to address adequate detection and quantification limits, suitable reproducibility and repeatability for a wide range of smoke constituents (from $\mathrm{mg}$ to $\mathrm{ng}$ per cigarette). They are inadequate to deal with the reactive and dynamic nature of cigarette smoke. It has been suggested that artefacts in the smoke collection processes could be responsible for some of these unexplained features, for example, the use of ascorbic acid as a trapping media has led to artificial formation of tobacco nitrosamines [14].

To understand the dynamic and reactive nature of the smoke formation processes, real-time (or on-line) measurements, including those capable of directly sampling smoke at various locations inside a burning cigarette rod, have proved to be more useful $[1,15]$. With advances in modern analytical techniques (e.g. various laser-based and other fast mass spectrometry), real-time smoke analyses with improved LODs and LOQs have become more accessible. A few examples of recent real-time experiments are given below to illustrate the advantages as well as challenges in conducting this type of work.

A key requirement for analysing cigarette smoke in real time is that the analytical system employed must have adequate time and mass resolutions to identify targeted smoke analytes. For a typical 2-s puff, the sampling frequency for each analyte should be around $10 \mathrm{~Hz}$ or greater. This requirement on time resolution can be easily fulfilled by modern analytical (and associated data management) systems. Thus, real-time smoke formation studies have been reported using systems such as Fourier-transform infrared spectroscopy [16], quantum-cascade infrared laser spectroscopy [17-20], dual infrared tuneable diode-laser systems [21-24], gas chromatography-mass spectrometry with a special puff-resolved trapping mechanism [25-28], resonance-enhanced multiphoton ionisation-time of flight mass spectrometry (REMPI-TOFMS) and single-photon ionisation-time of flight mass spectrometry (SPI-TOFMS) [29-36]. These studies can be broadly classified into two types: those dealing with puff-by-puff quantification of smoke analytes and those which are more mechanistically oriented and investigate the formation processes of individual smoke analytes.

For example, a series of studies have been carried out using a dual-infrared tunable diode-laser system to study the real-time smoke constituents [17-24]. More specifically, Plunkett et al. [23] investigated the interaction between formaldehyde and ammonia during a 2-s generation of mainstream smoke. The system achieved a millisecond resolution for the four target species and avoided the ambiguity normally associated with the mass spectrometric separation of formaldehyde and nitric oxide, both present in the cigarette smoke. The technique produced real-time profiles for formaldehyde, ammonia and ethylene on a puff-by-puff basis, which proved that the reaction between formaldehyde and ammonia did occur, and this was influenced by the cigarette lighting method. In addition to confirming that the highest yield of formaldehyde occurs in the first puff, the individual profiles for the three species (formaldehyde, ammonia and ethylene) showed different peak shapes during the 2-s puff, a fact indicating possible interaction between these analytes and the tobacco rod.

In another example, Shi et al. [17] used quantumcascade infrared laser spectroscopy to study real-time formation of volatile smoke analytes in both mainstream and sidestream smoke. In this study, a $36 \mathrm{~m}$ long $/ 0.3 \mathrm{~L}$ volume multiple pass absorption gas cell was used to achieve a 0.1 -s flow resolution for the mainstream smoke and $0.4 \mathrm{~s}$ for the sidestream smoke. The concentration profiles for a number of volatile smoke compounds (ammonia, ethylene, nitric oxide and $\mathrm{CO}_{2}$ ) were monitored simultaneously in the mainstream and sidestream smoke with a $20-\mathrm{Hz}$ data acquisition rate. The recorded puff profiles after a 2-s puff all lasted for about $2.5 \mathrm{~s}$, with the two combustion gases nitric oxide and $\mathrm{CO}_{2}$ displaying similar characteristics. However, the concentration of $\mathrm{NH}_{3}$ showed a significant increase during the later puffs, and this was attributed to $\mathrm{NH}_{3}$ absorption by the tobacco rod in the earlier puffs and its subsequent thermal desorption. The ethylene profile showed the highest peak concentration in the first puff. The $\mathrm{CO}_{2}$ peak decayed over a period of about $4.5 \mathrm{~s}$; this was attributed to the long flow response time in the $\mathrm{CO}_{2}$ analyser. The profiles of the four species in both the mainstream and sidestream smoke streams were interrelated during and around the 2-s puff periods, a feature demonstrating the intricate connection between the two smoke formation processes.

The application of REMPI-TOFMS and SPI-TOFMS to cigarette smoke studies takes advantage of the "soft" ionisation mechanism and extends real-time measurements to a wide variety of compounds (e.g. $\mathrm{NH}_{3}, \mathrm{NO}$, furan, benzene, limonene and nicotine) [29-36]. Like some of the earlier studies, these experiments have shown that this type of techniques can also be used to obtain good quantitative results. However, the real strength of these techniques remains in their ability to unravel complex dynamic interactions between smoke components and cigarette design features. In a recent example [34], the technique was applied to include on-line particle size analysis to study the real-time smoke aerosol properties as well as smoke compositions. For example, the presence of a particle filter was found to have 
different effects on gaseous compounds, i.e. some were totally removed (phenol), some partially removed (styrene) and some essentially unaffected (acetaldehyde). For aerosol particles, the count median diameter decreased from puff to puff and was found to be strongly dependent on the smoking regime and ventilation level of the cigarette filter.

A common challenge for real-time smoke analysis is the need to design a suitable smoke sampling interface, which takes into account the flow characteristics of a 2-s puff (during and interpuff). For example, Parrish et al. [16, 22] pointed out that a conventional Cambridge filter-pad holder used for routine smoke analyses can have as much as $14 \mathrm{~mL}$ of "dead" volume, which traps volatile species and allows condensation of less volatile analytes. This presents a much bigger issue for real-time measurements than for routine smoke analyses. For real-time smoke profiling, the use of switches, valves or unheated surfaces prior to chemical detection should be avoided as they tend to cause condensation or entrapment. Adam et al. [29, 31] demonstrated that a significant amount of volatile species are trapped in the sampling system and carried into the subsequent puffs. To minimise the dead volume effect, repeated clearing puffs are taken to prevent trapped volatile species from entering the subsequent puffs.

In the work of Shi et al. [17], a flow control was used with pressure feedback loop to avoid downstream valves between the cigarette and the sampling orifice (into an infrared analyser). To achieve this, a dilution/bypass flow was introduced so that when the total dilution and bypass flows matched the flow going through the orifice, there was no pressure gradient across the cigarette. By temporarily reducing the bypass flow to a preset value, flow was diverted through the lit cigarette causing a puff to occur. One drawback of this procedure was that only a square-wave puff profile was achievable rather than the bell-shaped puff profile, which is typically specified by standardised machinesmoking methods $[12,13]$ and also approximated by human smokers. Shi et al. [17] applied a total flow of 3.84 standard litres-per-minute through the sampling orifice; such a large flow rate was necessary in the multiple pass cell to achieve the 0.1-s flow resolution. However, the high flow rate could make it difficult to maintain an exact flow balance during a 2 -s to produce a $35-\mathrm{mL}$ puff. During interpuff smouldering periods, a flow imbalance of as little as $1 \mathrm{~mL} / \mathrm{min}$ could be sufficient to cause volatile species to be flushed from the cigarette rod.

For cigarette combustion, smouldering and puffing differ fundamentally and are known to produce smoke of quite different compositions [1]. So far, most published real-time measurements have focused on smoke generation during puffing, as this is more relevant to mainstream smoke yields. Furthermore, smouldering burn (either before or after the puffing) is generally treated as a completely separate process, assuming that smouldering has no impact on the mainstream smoke formation $[1,35]$. This prevailing understanding has also influenced the way most on-line measurements have been conducted, i.e. a burning cigarette is usually isolated from the detection unit during the smouldering phase, sometimes to allow clearing puffs to be carried out. A different approach was taken in this work, which investigated the possible contribution by smouldering burn to the mainstream smoke.

\section{Experimental}

AirSense compact (ion-molecule reaction) mass spectrometer The instrument (www.vandfna.com) is a portable quadrupole mass spectrometer with combined chemical and electron ionisation. It has been used in applications such as automobile exhaust and environmental air pollution studies [37]. Its chemical ionisation source is equipped with a choice of three ionisation gases, $\mathrm{Hg}(10.44 \mathrm{eV}), \mathrm{Xe}$ $(12.13 \mathrm{eV})$ and $\mathrm{Kr}(14.00 \mathrm{eV})$. Their ionisation levels are close to that used in single-photon ionisation (ca. $10.51 \mathrm{eV}$ ) [29-36], and much lower than that usually used under electron impact ionisation $(70 \mathrm{eV})$. The time resolution of the system ranges from ca. $75 \mathrm{~Hz}$ for a single analyte to approximately $10 \mathrm{~Hz}$ for eight analytes. In this study, up to six volatile smoke constituents $(\mathrm{m} / \mathrm{z} 44$, acetaldehyde; $\mathrm{m} / \mathrm{z} 58$, acetone; $m / z 44$, carbon dioxide; $m / z 30$, nitric oxide; $m / z 54$, 1,3 butadiene; $\mathrm{m} / \mathrm{z}$ 68, isoprene; $\mathrm{m} / \mathrm{z} 92$, toluene; $\mathrm{m} / \mathrm{z} 78$, benzene) were scanned during a typical 2-s puff. The mass resolution of the AirSense is around $0.1 \mathrm{~m} / \mathrm{z}$; therefore, it cannot distinguish isobaric compounds or isomers.

Interface between cigarette and AirSense A purpose-built sample holder is used as the interface between a burning cigarette and the AirSense inlet (Fig. 1). Smoking was carried out by a single-port smoking machine (RM1 type, Borgwaldt $\mathrm{Kc}, \mathrm{GmbH})$. The key features of the system are as follows:

- Puff-resolved measurements are conducted as close as possible to the mouth end of the cigarette filter, to minimise carry-over effects due to the dead volume effect. Another benefit is that the detection of any species within the cigarette can be conducted at a higher sensitivity without any buffering caused by subsequent smoke passage.

- Smoke constituent evolution is monitored continuously during puffing and smouldering without the need to isolate the cigarette, thus minimising interruption to the cigarette combustion processes. This feature is different from how cigarettes are normally smoked by routine smoking machines and allows the cigarette to be 
Fig. 1 A schematic drawing of the sampling system (not to scale)

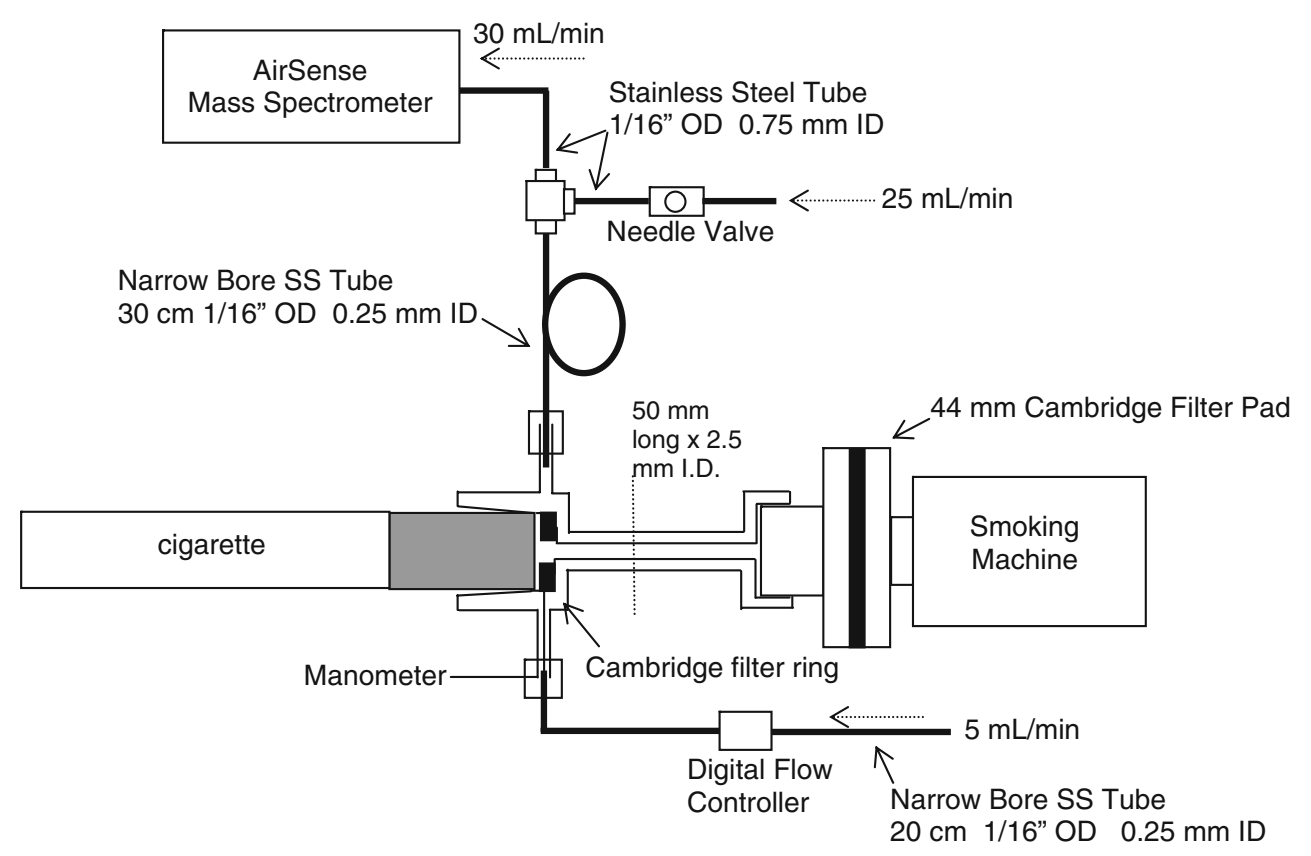

monitored under conditions that are more close to real human smoking.

- To achieve the objective of maintaining a natural smouldering cigarette, the mouth end of the cigarette filter is always maintained at atmospheric pressure during smouldering, which allows volatile species to form and to build up without blocking the filter mouth end.

A schematic diagram of the interface and the entire system is shown in Fig. 1. During the operation, the interface is kept at room temperature. The flow into the AirSense inlet (set at $30 \mathrm{~mL} / \mathrm{min}$ in this study) is divided into two paths. The major portion of the flow $(25 \mathrm{~mL} / \mathrm{min})$ comes from the ambient laboratory air (unfiltered). This is balanced by a small airflow $(5 \mathrm{~mL} / \mathrm{min})$ in and out of the cigarette holder. The exact balance of this $5 \mathrm{~mL} / \mathrm{min}$ flow ensures that there is no pressure gradient across the cigarette during the smouldering burn. This flow should be as small as possible to give the AirSense an adequate response (see below). During this work, the airflow of $5 \mathrm{~mL} / \mathrm{min}$ was controlled by a digital mass flow controller (Aalborg, model GFM17 type). A manometer (Borgwaldt Technik GmbH, model R24.01) was used to ensure atmospheric pressure when a cigarette was not puffed.

The inlet of the AirSense is placed at $90^{\circ}$ to the direction of the smoke flow. Together with a small Cambridge filter ring (described below), the inlet mainly samples volatile species while allowing the bulk of the smoke aerosol to flow through to another conventional Cambridge pad holder. The internal space between the AirSense inlet and the interface is less than $0.02 \mathrm{~mL}$, another feature important to a good response. The small Cambridge filter ring (O.D. $8.0 \mathrm{~mm}$, ID $3.0 \mathrm{~mm}$ ) is cut from a 44-mm-diameter
Cambridge filter pad with a purpose-built cutter. The much reduced volume of the Cambridge filter ring significantly minimises the amount of volatile species trapped. All these features enable the system to be operated continuously throughout a number of puffing/smouldering cycles without the need for clearing puffs. For the experiments in this work, a clean Cambridge ring was used for every new cigarette smoked. The conventional 44-mm Cambridge filter pad and its holder (Fig. 1) are positioned between the interface, and the single-port smoking machine is connected by a stainless steel tube (approximately $50 \mathrm{~mm}$ long and $2.0 \mathrm{~mm}$ ID). The 50-mm-long tube sufficiently restricts any backward diffusion of vapour phase species from the large Cambridge filter pad (see below). The system can be operated under two modes, a continuous or interrupted mode. In the continuous mode, a cigarette is lit either before or after being inserted into the holder. The AirSense is switched on and left to continuously monitor the analytes selected during each puff and smouldering cycle until the cigarette or the experiment is finished. In the interrupted mode (intended to simulate human smoking), a lit cigarette is removed from the holder after a 2-s puff for a specified period of time before beingre-inserted for the next puff. All the results reported in this paper were obtained using the continuous mode.

Validation of the system To assess the possibility of volatile desorption and backward diffusion from the large Cambridge pad had, a 44-mm Cambridge pad with ca. $19 \mathrm{mg}$ total particulate matter deposited from smoking a $3 \mathrm{R} 4 \mathrm{~F}$ research reference cigarette (University of Kentucky, Kentucky Tobacco Research and Development Centre) under $35 \mathrm{~mL}, 2$-s puffs once every $30 \mathrm{~s}$, was inserted into 
Fig. 2 Monitoring the extent of release of volatile species from a used 44-mm-diameter Cambridge filter pad

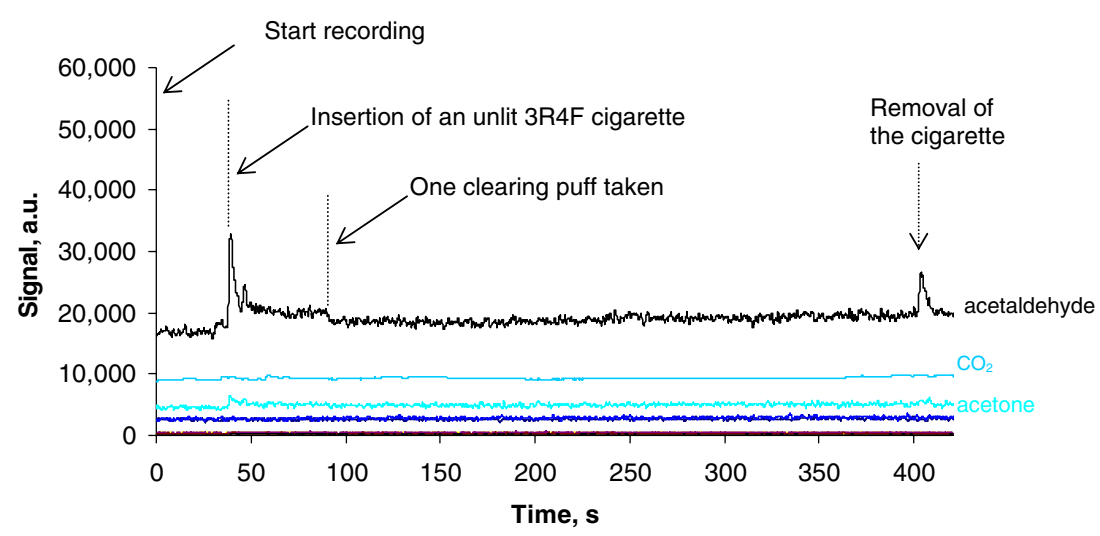

the 44-mm pad holder. In the interface, another 3R4F cigarette was inserted but not lit. The signals for a number of volatile species were recorded, and the results are shown in Fig. 2. Upon insertion of the unlit cigarette, small peaks (at ca. $45 \mathrm{~s}$ ) were observed, particularly for acetaldehyde. This was attributed to the release of tobacco volatile species from the cigarette. At about $90 \mathrm{~s}$, a clearing puff ( $35 \mathrm{~mL}, 2 \mathrm{~s}$ duration) was taken, which resulted in a small drop in the acetaldehyde signal. For the remaining $300 \mathrm{~s}$, there was no significant change for any of the signals monitored, confirming that the release and transfer of the volatile species from the smoked Cambridge filter pad was negligible.

To illustrate the response time of the system and also the fact the narrow-bore stainless steel tubes linking the AirSense and the interface holder introduces no peak separation, Fig. 3 displays the detection of a carbon dioxide $(\mathrm{m} / \mathrm{z} 44,5 \mathrm{ppm})$ and toluene $(\mathrm{m} / \mathrm{z} 92,1 \mathrm{ppm})$ mixture. The gas mixture was contained in a gas bag which was connected to the interface. A number of $35-\mathrm{mL}$ and 2-s duration puffs were taken. The example show in Fig. 3 confirms that there is virtually no separation between the two compounds, and the rise of the peaks was sufficiently fast to discriminate peak shape differences in relation to a 2-s puff.

Smoke analytes The volatile compounds studied in this work are listed in Table 1, together with their mainstream

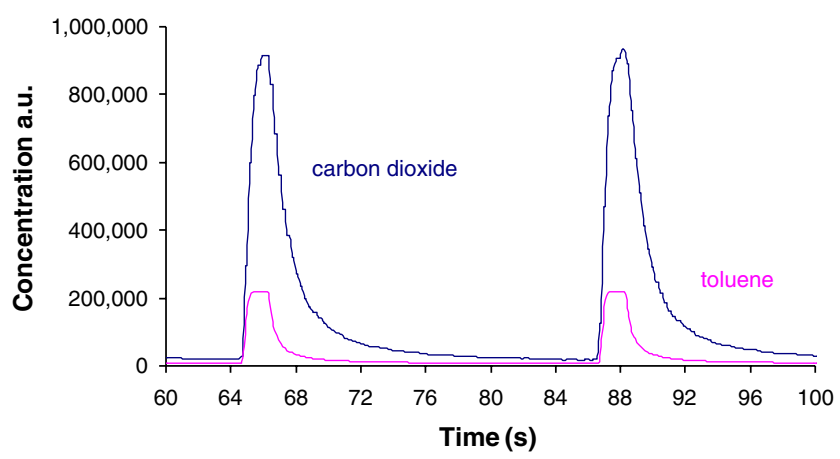

Fig. 3 Release of carbon dioxide $(44 \mathrm{~m} / \mathrm{z})$ and toluene $(92 \mathrm{~m} / \mathrm{z})$ from a gas bag mixture using $35-\mathrm{mL}, 2-\mathrm{s}$ puffs smoke yields as measured under the ISO smoking parameters for the 3R4F cigarettes tested. The selected analytes represent permanent gases from combustion (nitric oxide and carbon dioxide) and organic species with high (1,3 butadiene and isoprene) and moderate volatilities (acetone, acetaldehyde, benzene and toluene). Most of these volatile organic species are known toxicants in cigarette smoke [11], and some of them have been studied before by other real-time detection methods (e.g. [18, 20, 29, 30]). In this work, carbon dioxide was detected using electron impact ionisation, and the other analytes were detected using ionised $\mathrm{Hg}$ gas source. The ionisation potential of $\mathrm{Hg}$ $(10.44 \mathrm{eV})$ is higher than that of acetaldehyde $(10.23 \mathrm{eV})$ but lower than that of carbon dioxide $(13.77 \mathrm{eV})$; therefore, the detection of acetaldehyde has no interference from carbon dioxide.

Some details about the 3R4F research reference cigarette can be found from the webpage of the supplier (University

Table 1 Mainstream machine-smoking yields (plus standard deviation) of the selected volatile compounds for 3R4F research reference cigarette under ISO smoking regime

\begin{tabular}{lcc}
\hline Analyte & Unit & 3R4F cigarette \\
\hline Nitric oxide & $\mu \mathrm{g} / \mathrm{cig}$. & $191.2 \pm 9.3$ \\
Acetaldehyde & $484.6 \pm 44.9$ \\
Acetone & $250.1 \pm 24.9$ \\
Benzene & $32.8 \pm 4.4$ \\
Toluene & $49.3 \pm 9.9$ \\
1,3 Butadiene & $23.6 \pm 4.9$ \\
Isoprene & $134.9 \pm 27.9$ \\
TPM & $9.94 \pm 0.47$ \\
Tar & $8.31 \pm 0.37$ \\
Carbon monoxide & $11.06 \pm 0.54$ \\
Carbon dioxide ${ }^{\mathrm{a}}$ & \\
Nicotine & & - \\
& & $0.722 \pm 0.03$ \\
\hline${ }^{a}$ Carbon dioxide is not routinely measured. Its inclusion in this study \\
was to demonstrate the resolution of the technique. Its level in \\
cigarette mainstream smoke is typically three times that of carbon \\
monoxide (by weight) [1]
\end{tabular}


Table 2 The main design parameters of 3R4F research reference cigarette

\begin{tabular}{ll}
\hline Analyte & 3R4F Cigarette \\
\hline Circumference, mm & 24.8 \\
Total filter length, mm & 27.0 \\
Total pressure drop, mm $\mathrm{H}_{2} \mathrm{O}$ & 134 \\
Tip ventilation (\%) & 30 \\
Cigarette length, mm & 84 \\
Total weight, g & 1.06 \\
Cigarette paper permeability, CU & 24 \\
Tobacco rod length, mm & 57 \\
Filter type & Cellulose acetate \\
\hline
\end{tabular}

Data taken from www.ca.uky.edu/refcig/3R4F\%20Preliminary $\%$ 20Analysis.pdf (accessed on 9 December 2009)

of Kentucky, Kentucky Tobacco Research and Development Centre). Its main design features are listed in Table 2. All the cigarettes tested were conditioned at $22 \pm 2{ }^{\circ} \mathrm{C}$ and $60 \pm 3 \%$ RH for a minimum of $48 \mathrm{~h}$.

\section{Results and discussion}

Smouldering cigarettes The results in this section were obtained from free smouldering cigarettes. Figure 4 presents the results for seven analytes from a 3R4F cigarette (separated into two figures for clarity). The cigarette was lit without taking a puff to keep the tobacco rod free from smoke contamination. After the lit cigarette was inserted, there was a small rise in the background level for a number of analytes at around $20 \mathrm{~s}$. The background signals then stayed relatively constant until about $400 \mathrm{~s}$ before a gradual increase in concentration for all the analytes were observed. This continued to about $710 \mathrm{~s}$, at which point the burn line had reached 3-mm-plus over-tipping (an impermeable paper wrapper that holds filter and tobacco rod together), and the cigarette was removed from the interface holder. The acetaldehyde and carbon dioxide plots show close similarities. However, as previously explained, the detection of acetaldehyde was free from carbon dioxide interference despite their closely matched mass/charge ratios. The likely contribution of acetaldehyde to the carbon dioxide measurement was insignificant because of the much higher carbon dioxide concentration in cigarette smoke (per 3R4F cigarette, tens of $\mathrm{mg}$ for carbon dioxide as oppose to $0.5 \mathrm{mg}$ for acetaldehyde; Table 1). The closely matched peak heights for the two species in Fig. 4 are caused by the different ionisation techniques used.

The concentration rise in Fig. 4 lasted for about 300 s, during which time about $16 \mathrm{~mm}$ of the tobacco rod was consumed by smouldering. Thus when the analytes were

Fig. 4 Increasing concentrations of volatile species from the mouth end of the cigarette filter. The 3R4F cigarette was lit without taking a puff, then allowed to smoulder to $3 \mathrm{~mm}$ before the over-tipping. a Acetaldehyde, carbon dioxide, acetone and nitric oxide; $\mathbf{b} 1,3$ butadiene, isoprene, benzene and toluene
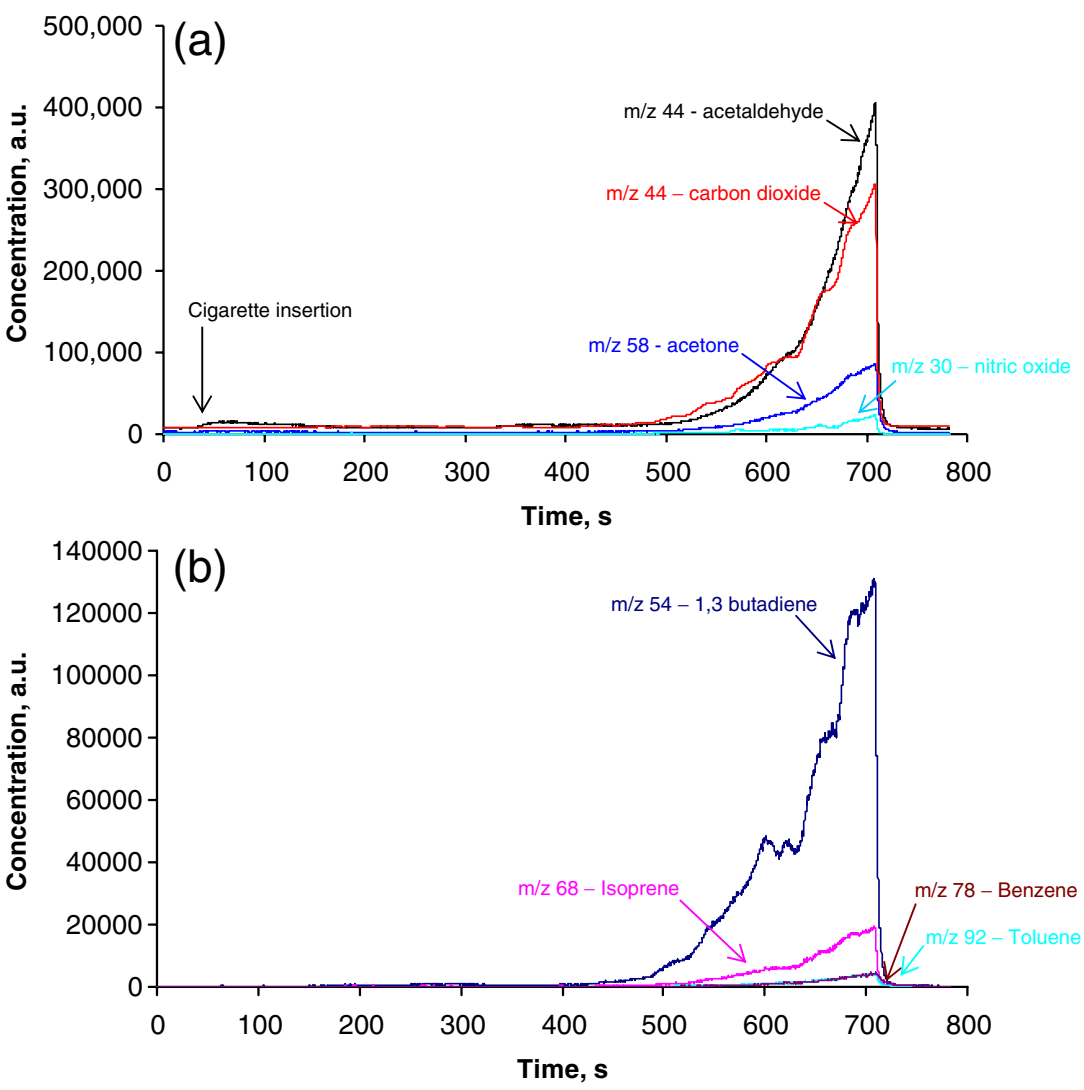
first detected at the mouth end of the cigarette filter, they had passed along $46 \mathrm{~mm}$ of the cigarette rod $(16 \mathrm{~mm}$ tobacco rod $+3 \mathrm{~mm}$ over-tipping $+27 \mathrm{~mm}$ filter), or approximately $2.3 \mathrm{~mL}$ in volume. The composition of this trapped smoke and its potential contribution to mainstream smoke, if the cigarette is puffed, is important to investigate.

Figure 5 shows the effect of the cigarette filter on the build up of volatile species. The filter in $3 \mathrm{R} 4 \mathrm{~F}$ cigarette is made of a single segment of cellulose acetate fibre with the main purpose of reducing the total particulate matter. This filter segment has a finite resistance to flow (called draw resistance or pressure drop). This experiment was designed to show the effect of this draw resistance on the accumulation of volatile species. For this purpose, one $3 \mathrm{R} 4 \mathrm{~F}$ cigarette had its cigarette filter removed, and this was compared with a normal 3R4F cigarette. Both cigarettes were allowed to smoulder to the same remaining rod length, i.e. approximately $30 \mathrm{~mm}$. For an equal rod length, the pressure drop of the filter is greater than that of the tobacco rod; therefore, the pressure drop of the $27-\mathrm{mm}$ filter $+3-\mathrm{mm}$ tobacco rod (filter attached) is greater than that of the $30-\mathrm{mm}$ tobacco rod (filter removed). This is clearly reflected by the results shown in Fig. 5: Removing the cigarette filter increased all the peak concentrations despite the fact there was less tobacco burnt for the non-filtered cigarette. The volatile buildup within the cigarette rod is evidently sensitive to the downstream pressure.

The results presented so far demonstrate a significant entrapment of the volatile species within the cigarette rod (tobacco rod and filter combined). The extent of the entrapment is shown to be sensitive to the presence and the design of the cigarette filter. It is known that the smoke formed during smouldering is more concentrated than that formed during puffing [1] and that some of the trapped species are highly reactive and will change during the time they are trapped. The presence of these dynamic smoke constituents and their interaction with the tobacco rod is one of the main reasons that mainstream cigarette smoke displays some complicated behaviours [1-3].

Individual puff-resolved experiments The experiments in this section were aimed at assessing the contribution of the trapped volatile species to mainstream smoke. The first example is shown in Fig. 6, with a 3R4F cigarette smoked under $35-\mathrm{mL}$ puff volume, 2-s duration and once every $60 \mathrm{~s}$. In Fig. 6a, the profiles of nitric oxide, toluene and acetone displayed a sharp rise upon puffing followed by a slow decay, which more or less lasted throughout the remaining 58-s interpuff interval. In most cases, the signals did not return to their original background levels, certainly
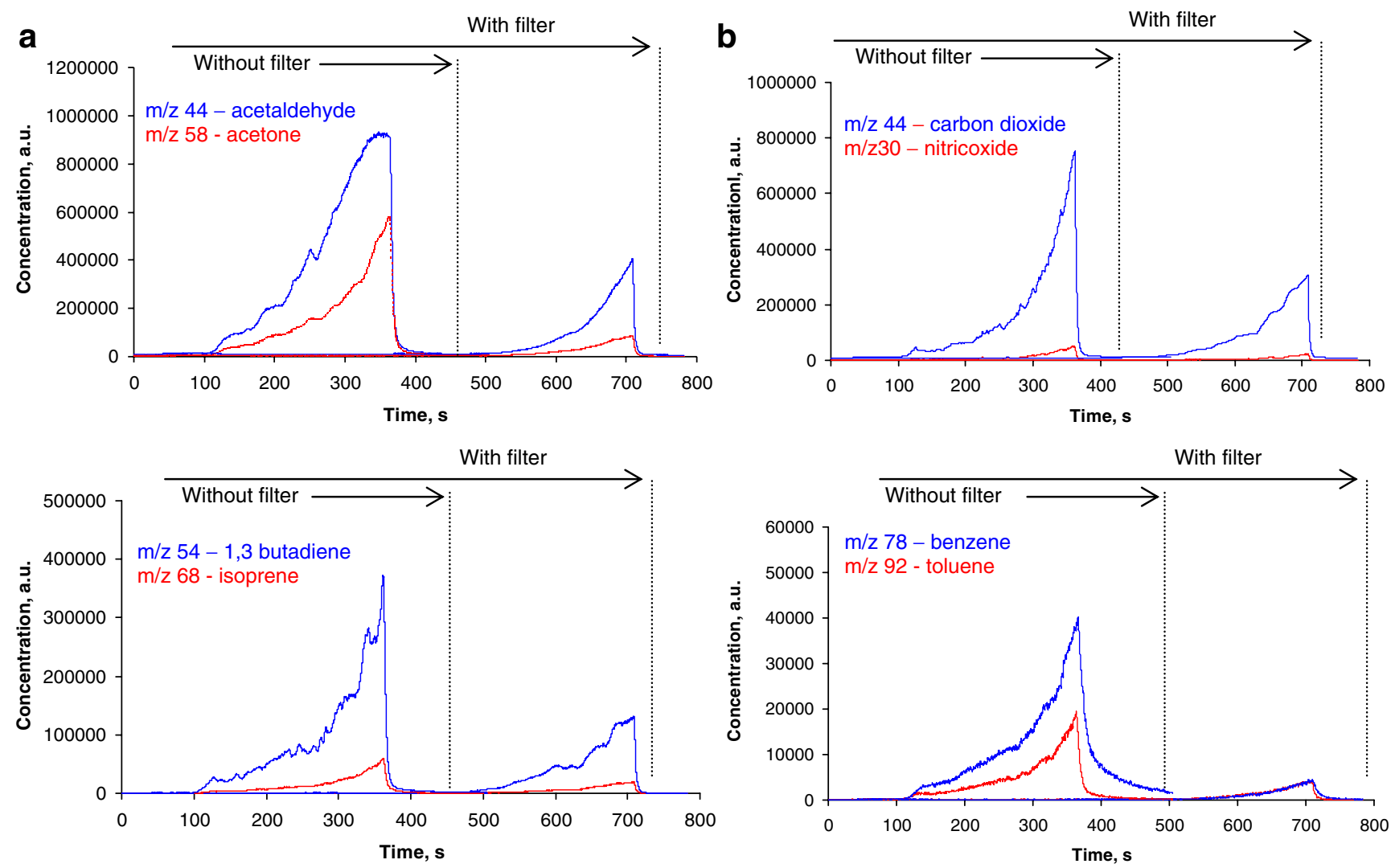

Fig. 5 Increasing concentrations of volatile species from a 3R4F cigarette with and without its filter. Both cigarettes were lit outside the holder, then allowed to smoulder to approximately $30 \mathrm{~mm}$ of the remaining rod length. a Acetaldehyde and acetone; $\mathbf{b}$ carbon dioxide and nitric oxide 
Fig. 6 Puff-resolved volatile profiles. One 3R4F cigarette was lit inside the holder with a lighting puff, followed by $35-\mathrm{mL} / 2$-s puffs every $60 \mathrm{~s}$ until reaching $3 \mathrm{~mm}$ before the overtipping. a Nitric oxide, toluene and acetone and $\mathbf{b} 1,3$ butadiene, isoprene, benzene and toluene
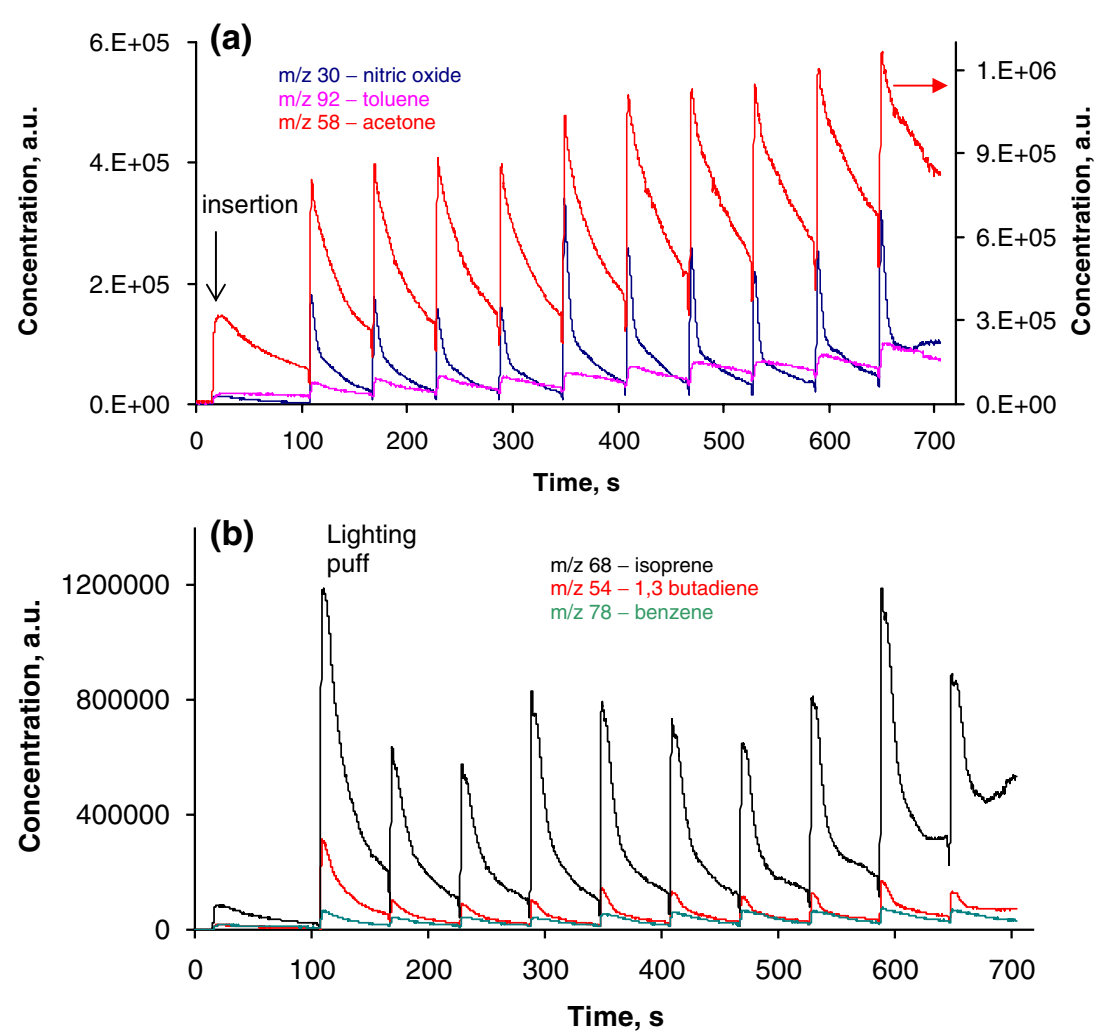

not at the end of the 2-s puff. This kind of behaviour has generally not been previously reported [17, 21-24, 29-34]. It is important to realise, however, that the fact these analytes displayed a continuous decay well beyond the end of the puff does not mean that they are part of the mainstream smoke. The mainstream smoke is only the part of the smoke passing through the cigarette filter within the puff duration ( $2 \mathrm{~s}$ in this case) under the action of puffing. What Fig. 6a shows is that the formation of these species does not exclusively occur during the puff and comes to an abrupt stop when the puff ends. In other words, the transition from puffing to smouldering is gradual without external interference. This is consistent with the accompanying physical processes, for example, the burning temperature after a puff (typically around $900{ }^{\circ} \mathrm{C}$ ) does not drop immediately back to the smouldering level (around $650^{\circ}$ C), and in fact it takes considerably longer than $2 \mathrm{~s}$ to return to the pre-puff level [1]. The peak concentrations produced by the lighting puff for isoprene, 1,3 butadiene and benzene (Fig. 6b) are significantly higher than those in most of the subsequent puffs, in contrast to nitric oxide, toluene and acetone (Fig. 6a), which show a gradual increase in concentration from puff to puff. This phenomenon, which has been documented before [21, 22, 31], is believed to occur for the former group of species when the tobacco experiences a larger thermal gradient (i.e. heated directly from room temperature without any pre-heating by the smouldering coal).
Figure 7 shows the levels of isoprene, 1,3 butadiene, benzene and toluene in the third and fourth puffs from a 3R4F cigarette smoked with 35-mL, 2-s puffs taken every 30 s. Figure $7 \mathrm{a}$ shows that the shapes of the profiles are quite different: isoprene and 1,3 butadiene peaked much earlier than did the two larger molecules (benzene and toluene). In Fig. 7b, which shows a magnified view of the third puff, the rise-to-peak times for isoprene and 1,3 butadiene were approximately $2 \mathrm{~s}$; this became $3 \mathrm{~s}$ for benzene and longer than $4 \mathrm{~s}$ for toluene. The decay for isoprene was slightly faster. These characteristic differences are due to the chemical nature of these analytes and their interactions with the cigarette rod. They would be masked if the cigarette is artificially isolated from the detection system either by a clearing flow or a valve. Understanding the reasons for these features may yield detailed information about their generation and transport mechanisms inside the burning cigarette.

In Fig. 8, detailed formation profiles for the seven analytes are presented for a 3R4F cigarette smoked with 35$\mathrm{mL}, 2$-s puffs taken once every $30 \mathrm{~s}$. The figures on the lefthand side are from the entire smouldering-puffing cycle (smoked until the burn line reached $3 \mathrm{~mm}$ before the tipping paper), while the right-hand side shows magnified views of the final puff profiles. The concentrations of the two combustion gases (carbon dioxide and nitric oxide) dropped nearly to background levels before the next puff. This agrees with the fact that these two small gases readily 
Fig. 7 Puff-resolved volatile profiles. One 3R4F cigarette was lit inside the holder with a lighting puff, followed by 35-mL, 2-s puffs once every $30 \mathrm{~s}$. Four organic volatiles are shown (1,3 butadiene, isoprene, benzene and toluene). a The third and fourth puff; $\mathbf{b}$ the third puff
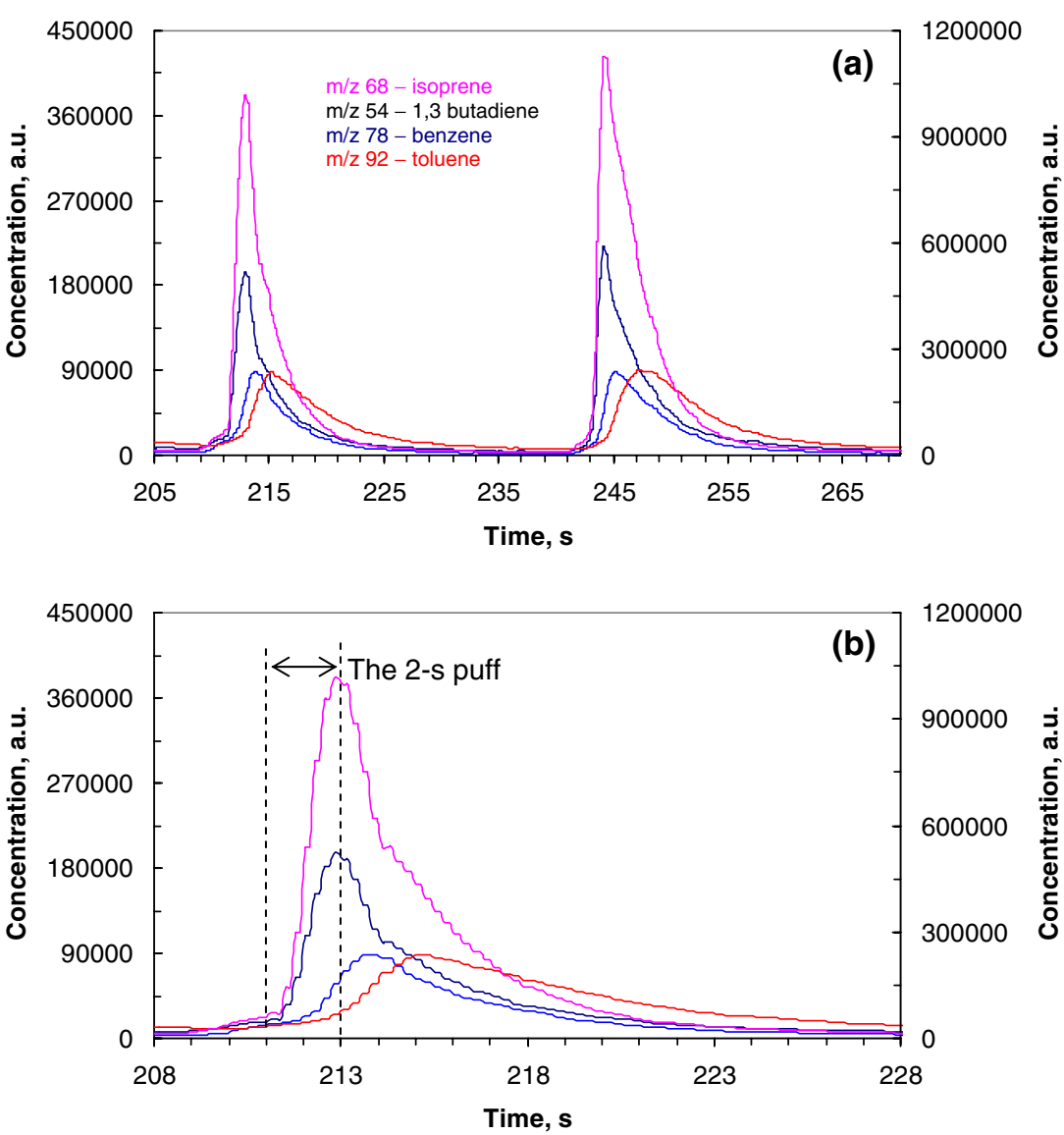

diffuse out of the cigarette rod [2]. The profile for carbon dioxide revealed multiple peaks for a number of later puffs. All the other organic species displayed a small and gradual increase in the background level on a puff-to-puff basis. The peaks of toluene and benzene are broader than those of the other analytes, consistent with the features shown in Fig. 7. The peak heights in Fig. 8 are in the order acetaldehyde $>$ isoprene $\geq$ acetone $\approx$ nitric oxide $\approx$ toluene $>$ benzene $>1,3$ butadiene, which broadly agrees with the mainstream smoke yields of these analytes for a $3 \mathrm{R} 4 \mathrm{~F}$ cigarette (Table 1).

Figure 9 shows the results obtained from another experiment where the puff duration was extended from 2 to $4 \mathrm{~s}$. This has the effect of reducing the gas flow rate during puffing for the same puff volume. As Fig. 9 shows, in the later puffs, the peaks for acetone, acetaldehyde, isoprene, toluene and benzene are split into two. For 1,3 butadiene and nitric oxide, the presence of the twin peaks were not convincingly resolved. The first peak, which was detected within the initial 0.5 to $1 \mathrm{~s}$ of the puff, was almost certainly due to the trapped analytes that were produced during the smouldering burn because of their immediate availability to the mouth end of the cigarette. The second and major peak was attributed to the puffing, because of its greater abundance and because it occurred at the same point in the puff as earlier puffs for which only one main peak was observed. The smouldering peak, although initially appearing as a small shoulder before the main peak, became more pronounced for the later puffs. This is consistent with the fact that trapped smouldering smoke would gradually become easier to detect at the mouth end. For the last one or two puffs, the height of the main puff peak relative to the smoulder peak increases (see, for example, the right-hand figures for toluene and benzene). This chiefly reflects an enhanced production of the main puff peaks for these later puffs [1, 4]. Characteristic changes in peak formation profiles have in fact been observed before, for example, the study by Crawford et al. [19]. In that study, Crawford et al. used on-line detection to study the evolution of $\mathrm{CO}$ and $\mathrm{CO}_{2}$ in mainstream and sidestream smoke for a cigarette with a special cigarette paper containing iron oxide pigments. Their results showed systematic changes in what appears to be multiple peaks for $\mathrm{CO}$ and $\mathrm{CO}_{2}$. With the iron oxide paper, a significantly lower initial peak for $\mathrm{CO}$ and $\mathrm{CO}_{2}$ was observed, possibly suggesting an enhanced diffusion during smouldering burn through the cigarette paper.

Figure 10a compares two consecutive benzene peaks at three different puff durations (2, 3 and $4 \mathrm{~s})$, all with a $35-\mathrm{mL}$ puff and taken at a similar rod position at 30-s puff duration. The effect of the systematic reduction in flow rate on the 

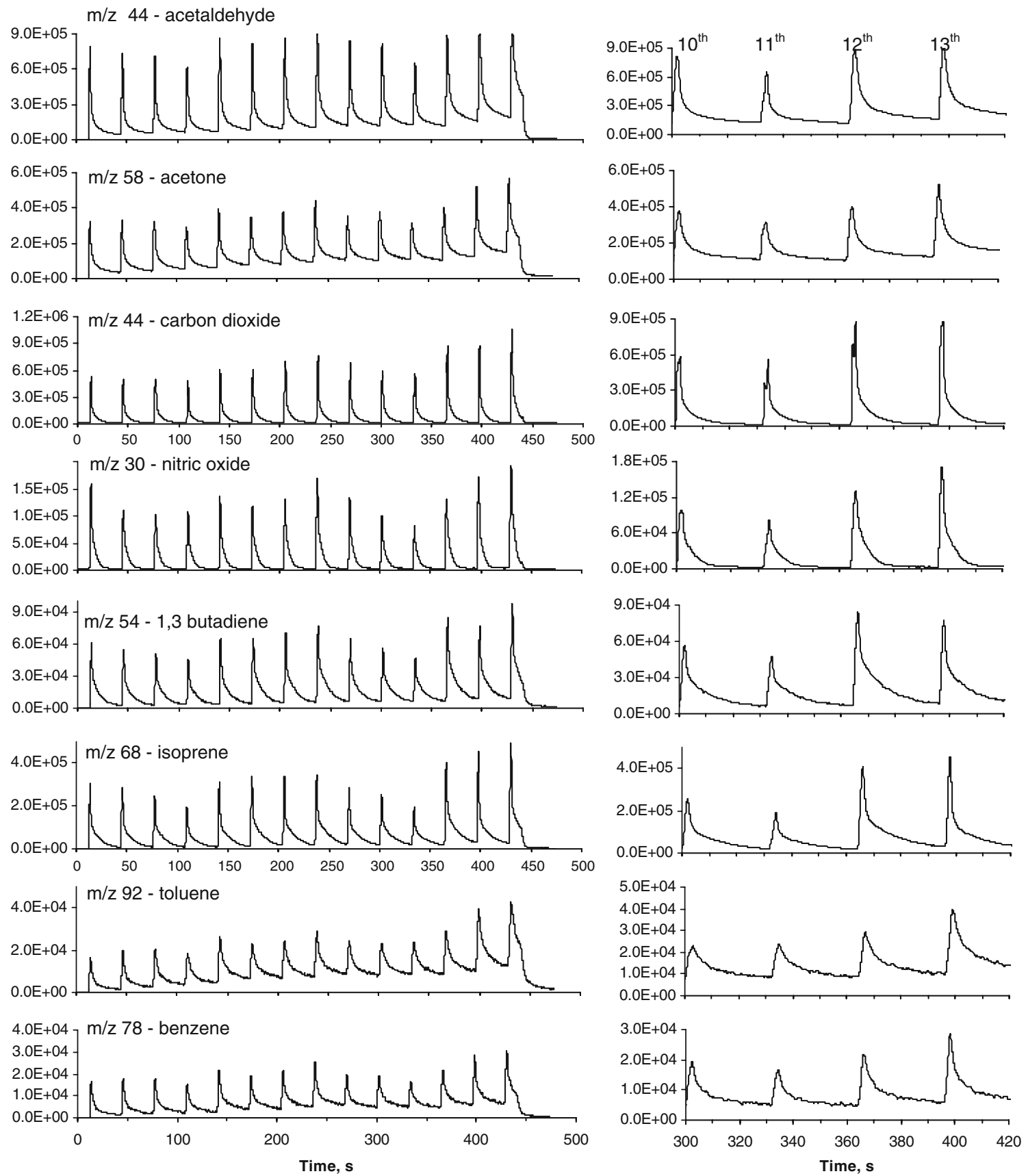

Fig. 8 Puff-resolved volatile profiles. One 3R4F cigarette lit outside the holder, followed by multiple puffs of $35 \mathrm{~mL} / 2 \mathrm{~s} / \mathrm{every} 30 \mathrm{~s}$. Left The whole profile; right four consecutive puffs

gradual build up of the smoulder peak is clearly demonstrated. The phenomenon shown in Fig. 10a is the direct result of the flow rate rather than the systematic reduction in the smouldering period (28 s for the 2-s puff, $27 \mathrm{~s}$ for the 3 -s puff and $26 \mathrm{~s}$ for the $4-\mathrm{s}$ puff), or the systematic reduction in the length of the tobacco rod burnt during smouldering, as the 26-s smouldering period produced the most significant smoulder peak.

Figure 10b shows a magnified view around a 4-s puff profile. By visual inspection, the contribution of the smouldering peak to the mainstream smoke is substantial; more can be explained by the relative volume of smoulder $(2.3 \mathrm{~mL})$ and puffing $(35 \mathrm{~mL})$. This indicates that the trapped smoke, similar to the sidestream smoke escaped the tobacco rod, is more concentrated than the mainstream smoke. It is possible that some smoulder-generated species are also part of the 2-s puffs peak; it is just that they are merged with the main puff peak under the puff flow and are therefore not resolved. Figure 10c illustrates the overall effect of a puff peak, extending far greater than the actual 

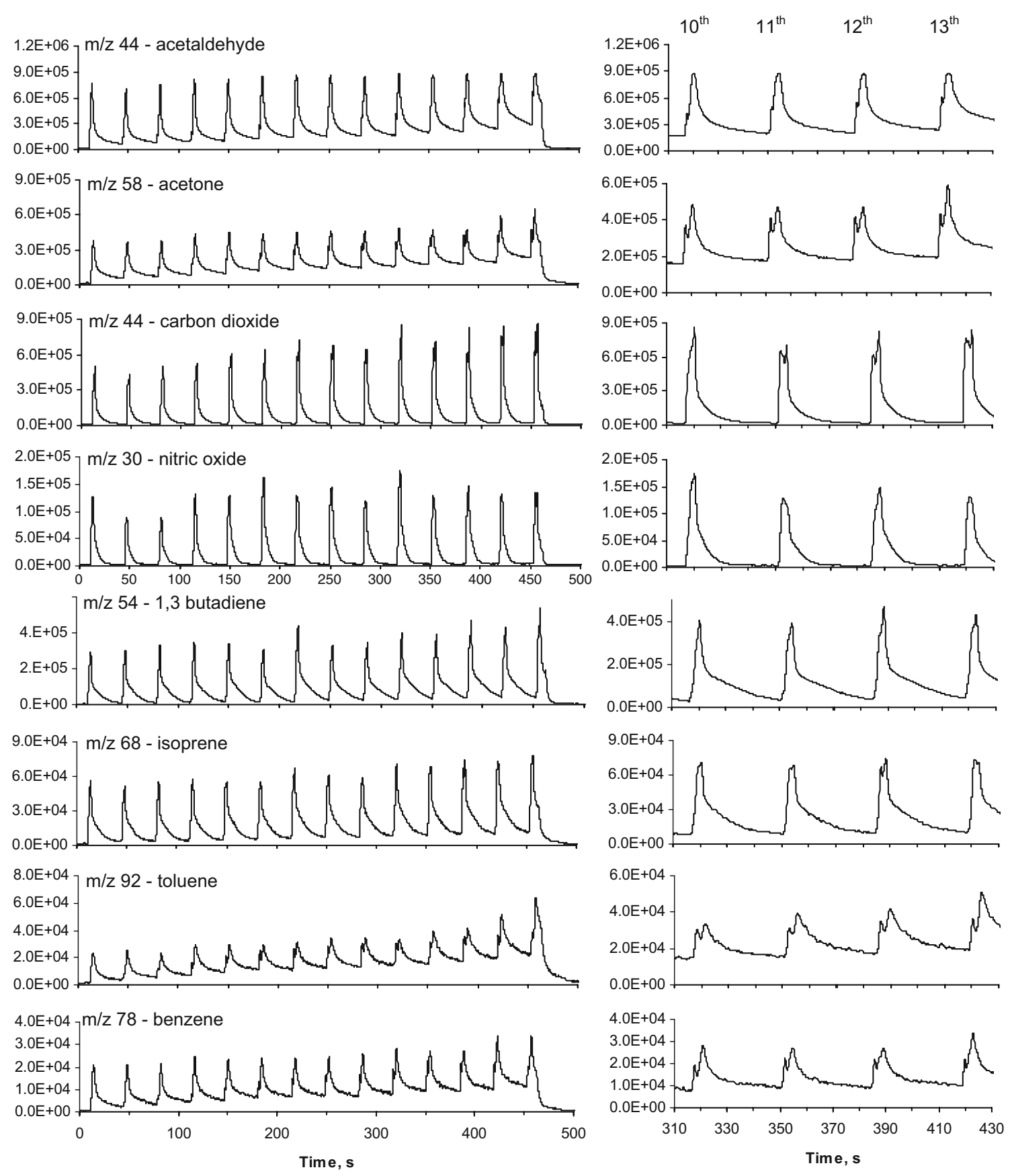

Fig. 9 Puff-resolved volatile profiles. One 3R4F cigarette lit outside the holder, followed by multiple puffs of $35 \mathrm{~mL} / 4 \mathrm{~s} / \mathrm{every} 30 \mathrm{~s}$. Left The whole profile; right four consecutive puffs

puff duration. Although the main purpose of this work is not quantitative, the effect of the puff on the overall smoke formation may be assessed by the relative ratio of the peak area under the puff/the total peak area under the puff interval (Fig. 11).

Figure 11 displays the relative ratio of the peak areas under a puff to that of under the total peak area (i.e. lasting the entire puff interval), for three analytes (acetaldehyde, benzene and carbon dioxide). These values are obtained under a single measurement; therefore, they should be treated as a trend rather than absolute values. For 3R4F cigarettes, the longer puff duration (4-s puff) increased the percentage of the smoke production over the total smoke produced as compared to the 2-s puff duration. Under equal peak height, a slowly drawn puff produces a broader peak shape, and the presence of the smouldering peak further enhances the smoke produced under the effect of puffing.

Smouldering, which only contributes to sidestream smoke, is usually regarded as a separate process from puffing. The entrapment of volatile species in the cigarette 
(a)
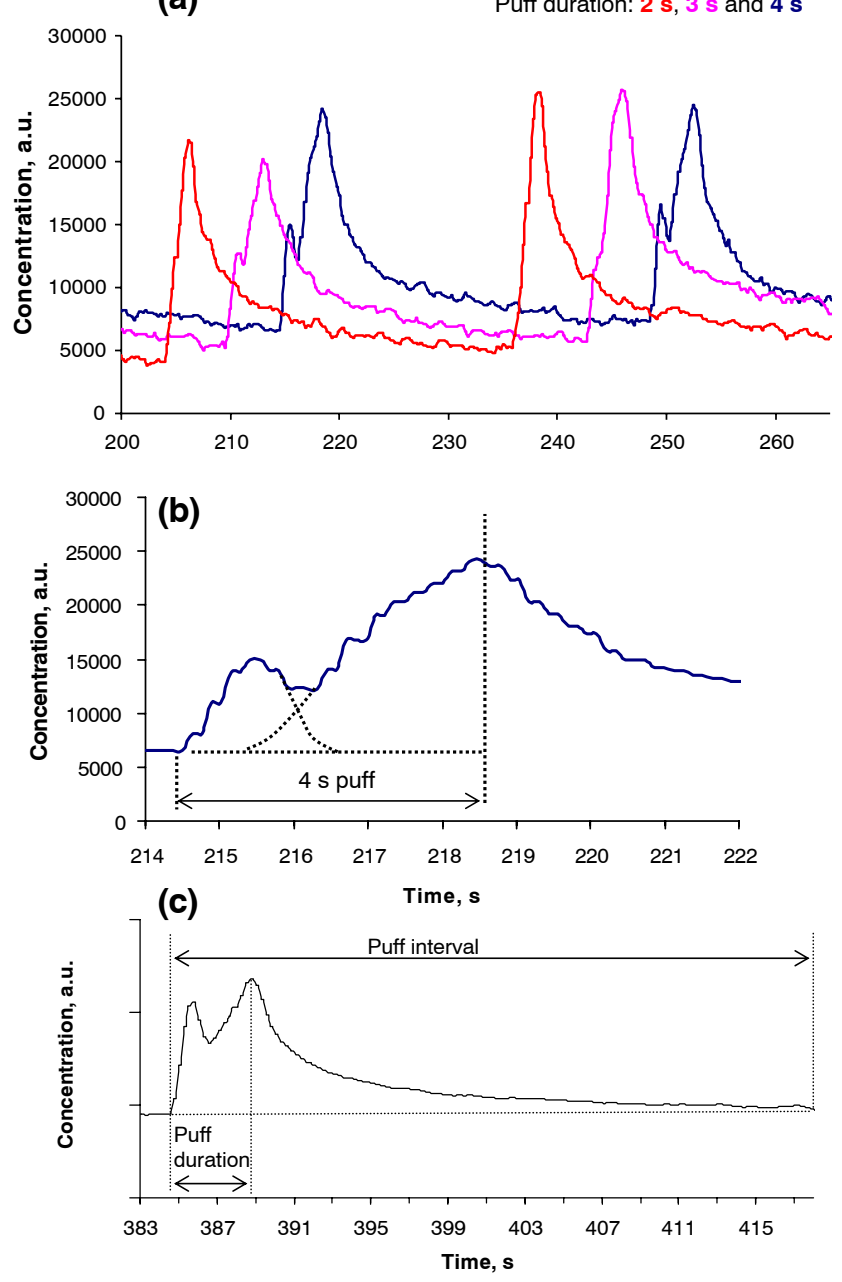

Fig. 10 Comparing a single puff profile of benzene acquired at three puff durations (a) and one individual puff (b). One 3R4F cigarette was lit outside the holder, then puffed in the holder with $35-\mathrm{mL}$ puffs once every $30 \mathrm{~s}$. c Time axis adjusted to allow easy viewing

rod during smouldering burn and their transfer to the mainstream smoke, as demonstrated here, reveal a clear connection between the two processes and calls for a more complex view of the smoke formation process. Since the extent of smoke entrapment was found to be sensitive to the pressure drops along different parts of the cigarette rod, any pressure barriers present downstream will affect the extend of the entrapment. Closing the mouth end intermittently during machine smoking, for example, is thought to suppress the extent of the build up of volatiles for an unventilated cigarette. For cigarettes with filter ventilation (e.g. most of the modern low-yield cigarettes), the pressure drop across the filter up to the ventilation point, and the extent of the filter ventilation are expected to influence the degree of smoke entrapment and its subsequent transfer to mainstream smoke.

The experimental setup used in this work is ideally suited to detect this phenomenon since there is a minimal dead volume between the mouth end of the filter and the smoke detection system. Extending the puff duration (i.e. reducing the flow rate) during puffing provides an opportunity to separate the two distinct sources of the smoke. The part of the smoke formed during puffing is mechanistically and kinetically dependent on combustion/ pyrolysis reactions, and therefore it takes longer for this smoke to be detected at the mouth end. Nevertheless, it remains to be part of the main body of the mainstream smoke. The effect of puff frequency may also influence the two sources of smoke; however, this was not studied.

\section{a}
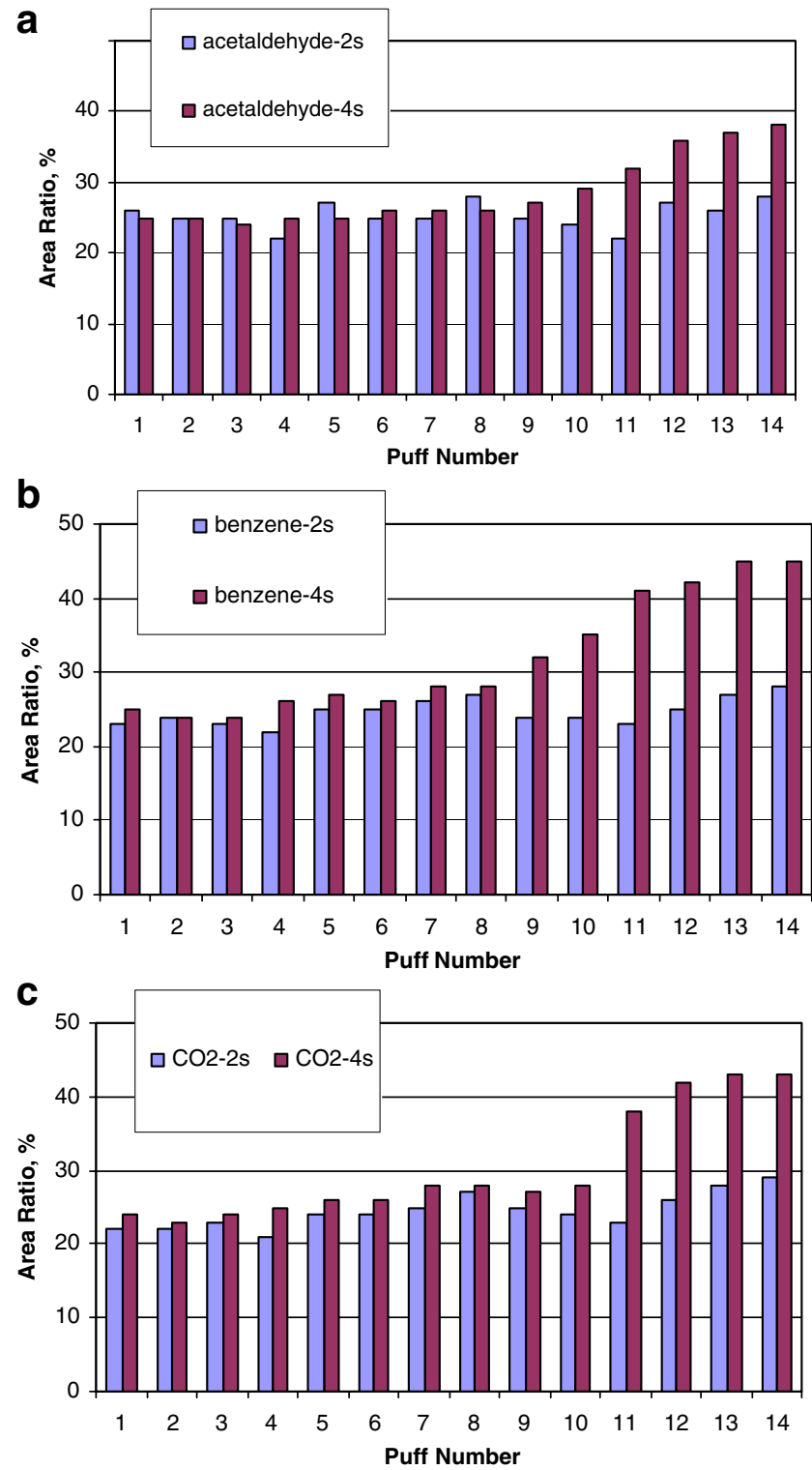

Fig. 11 Comparing integrated areas (Fig. 10c) for acetaldehyde (a), benzene (b) and carbon dioxide (c) acquired at three puff durations. One cigarette lit outside the holder, then followed by multiple puffs of $35 \mathrm{~mL}$ once every $30 \mathrm{~s}$. Results based on a single measurement to indicate trends only 
Understanding this phenomenon may help to explain some unidentified "source" or "sink" for some toxicant yields from cigarettes with widely different tar bands, as reported in the literature [9]. Most of the routine methods for determining toxicant yields involve smoking cigarettes on machines that valve off the end of the cigarette between puffs (but the cigarettes continue to smoulder) $[3,14]$. The mechanism revealed in this work predicts that, under standardised smoking conditions, different proportions of the trapped smoulder smoke are expected to contribute to the measured mainstream smoke yields: Greater contributions from smoulder smoke are expected for cigarettes with lower tar yields. This is because low machine-yield cigarettes tend to have higher levels of filter ventilation; and with closed-end smoke measurement systems, a higher level of filter ventilation encourages a greater extent of build up of the volatile species during smouldering-more work is needed to confirm this quantitatively. Despite the fact that the two sources of mainstream smoke are not separated during smoke analysis, the net effect can still be a higher contribution of the "hidden" source of smoke for the low machineyield cigarettes.

The relatively small volume of the cigarette rod (ca. 2 or $3 \mathrm{~mL}$ ) involved in the entrapment can have a disproportionately large influence on the smoke composition for a $35-\mathrm{mL}$ puff; this is because the smoulder derived smoke is more concentrated [1]. The quantity and composition of the trapped smoke are expected to depend on cigarette design (e.g. tobacco blend, rod diameter, cigarette paper, filter ventilation levels, etc.). Different smoking conditions (machine or human) are only expected to influence the extent of this smoulder source if they significantly alter the interpuff smouldering processes (e.g. very short puff intervals); different puff volumes or durations are unlikely to change the extent of this source. The presence of water within tobacco rod may also affect the trapping of watersoluble volatile species.

\section{Conclusions}

By using a specially designed real-time mass spectrometry system to study the puff-by-puff smoke formation of a number volatile organic species and two permanent gases, this work has revealed a significant contribution to mainstream smoke by trapped smoke generated during smouldering, a previously unreported phenomenon. The results challenge the conventional understanding that mainstream smoke is solely produced by the action of puffing, and also cast doubts on the "freshness" of at least part of mainstream smoke exiting the cigarette filter. In the context of mainstream smoke production, the connection between the smouldering and puffing processes through the interpuff period was intimately linked. Different types of volatile species (combustion gases, high or moderate volatility and the size of the molecules) have shown different characteristics. It is reasonable to assume that the presence and the design feature of the cigarette filter may also affect the phenomenon.

Acknowledgment Mr Barrie Frost was involved in the design of the interface used in this study. The authors are grateful to his valuable contribution to this work.

Open Access This article is distributed under the terms of the Creative Commons Attribution Noncommercial License which permits any noncommercial use, distribution, and reproduction in any medium, provided the original author(s) and source are credited.

\section{References}

1. Baker RR (1999) Smoke chemistry. In: Davis LD, Nielsen MT (eds) Tobacco: production, chemistry, and technology. Blackwell Science, Oxford, pp 398-439

2. Norman A (1999) Smoke chemistry. In: Davis LD, Nielsen MT (eds) Tobacco: production, chemistry and technology. Blackwell Science, Oxford

3. Borgerding M, Klaus H (2005) Exp Toxicol Pathol 57:43-73

4. Rodgman A, Perfetti TA (2008) The chemical components of tobacco and tobacco smoke. Taylor and Francis, USA

5. Baker RR (2006) Pror Energy Combust Sci 32:373-385

6. Baker RR (2004) Special Issue Food Chem Toxicol 42:S3-S83

7. Counts ME, Hsu FC, Laffoon SW, Dwyer RW, Cox RH (2004) Regul Toxicol Pharmacol 39:111-134

8. Counts ME, Morton MJ, Laffoon SW, Cox RH, Lipwicz PJ (2005) Regul Toxicol Pharmacol 41:185-227

9. Counts ME, Hsu FC, Tewes FJ (2006) Regul Toxicol Pharmacol 46:225-242

10. Morton MJ, Laffoon SW (2008) Regul Toxicol Pharmacol 51:1-30

11. Burns DM, Dybing E, Gray N, Hecht S, Anderson C, Sanner T, O’Connor R, Djordjevic M, Dresier C, Hainaut P, Jarvis M (2008) Tob Control 17:132-141

12. International Organisation for Standardisation 4387 (2000) Determination of total and nicotine-free dry particulate matter using a routine analytical smoking machine. International Organisation for Standardisation, Geneva

13. Canada H (1999) Determination of "Tar", nicotine and carbon monoxide in mainstream tobacco smoke, T-115. Health Canada, Ottawa

14. Dube MF, Green CR (1982) Recent Adv Tob Sci 8:42-102

15. Baker RR (1981) Pror Energy Combust Sci 7:135-153

16. Parrish ME, Lyons-Hart JL, Shafter KH (2001) Vib Spectrosc 27:29-42

17. Shi Q, Nelson DD, McManus JB, Zahniser MS, Parrish ME, Baren RE, Shafter KH, Harward CN (2003) Anal Chem 75:5180-5190

18. Baren RE, Parrish ME, Shafer KH, Harward CN, Shi Q, Nelson DD, McManus JB, Zahniser MS (2004) Spectrochim Acta Part A 60:3437-3447

19. Crawford DR, Parrish ME, Gee DL, Harward CN (2007) Spectrochim Acta Part A 67:4-15

20. Thweatt WD, Harward CN Sr, Parrish ME (2007) Spectrochimica Acta Part A 67:16-27

21. Parrish ME, Harward CN, Vilcins G (1986) Beitr zur Tabakforsch Int 13:169-181 
22. Parrish ME, Harward CN (2000) Appl Spectrosc 54:16651677

23. Plunkett S, Parrish ME, Shafer KH, Nelson D, Shorter J, Zahniser M (2001) Vib Spectrosc 27:53-63

24. Plunkett S, Parrish ME, Shafer KH, Shorter JH, Nelson DD, Zahniser MS (2002) Spectrochim Acta Part A 58:2505-2517

25. Thomas CE, Koller KB (2001) Beitr Tabakforsch Int 19:345-351

26. Takanami Y, Chida M, Hasebe H, Sone Y, Suhara S (2003) J Chromatogr Sci 41:317-322

27. Li S, Olegario RM, Banyasz JL, Shafter KH (2003) J Anal Appl Pyrolysis 66:156-163

28. Wagner KA, Higby R, Stutt K (2005) Beitr Tabakforsch Int 21:272-279

29. Adam T, Mitschkt S, Streibel T, Muhlberger F, Baker RR, Zimmermann R (2005) J Anal Appl Pyrolysis 74:454-464
30. Adam T, Ferge T, Mitschkt S, Streibel T, Baker RR, Zimmermann R (2005) Anal Bioanal Chem 381:487-499

31. Adam T, Mitschkt S, Streibel T, Baker RR, Zimmermann R (2006) Chem Res Toxicol 19:511-520

32. Adam T, Mitschkt S, Streibel T, Baker RR, Zimmermann R (2006) Anal Chim Acta 572:219-229

33. Mitschke S, Adam T, Streibel T, Baker RR, Zimmermann R (2005) Anal Chem 77:2288-2296

34. Adam T, McAughey J, McGrath C, Mocker C, Zimmermann R (2009) Anal Bioanal Chem 394:1193-1203

35. Muramatsu M (1981) Sci Papers Central Res Inst Japan Tob Salt Mon Corp 123:9-77

36. Adam T, Mitschke S, Baker RR (2009) Beitr zur Tabakforsch Int 23/24:203-226

37. Dearth MA (1999) Ind Eng Chem Res 38:2203-2209 